\begin{tabular}{|l|l|}
\hline Title & $\begin{array}{l}\text { Risk for Progression to Overt Hypothy roidism in an Elderly Japanese } \\
\text { Population with Subclinical Hypothyroidism }\end{array}$ \\
\hline Author(s) & $\begin{array}{l}\text { Imaizumi, Misa; Sera, Nobuko; Ueki, Ikuko; Horie, Ichiro; A ndo, Takao; } \\
\text { Usa, T oshiro; Ichimaru, Shinichiro; Nakashima, Eiji; Hida, Ayumi; Soda, } \\
\text { Midori; Tominaga, Tan; A shizawa, Kiy oto; Maeda, Renju; Nagataki, } \\
\text { Shigenobu; A kahoshi, Masazumi }\end{array}$ \\
\hline Citation & Thyroid, 21(11), pp.1177-1182; 2011 \\
\hline Issue Date & 2011-11-03 \\
\hline URL & http:/hdl.handle.net/10069/27443 \\
\hline Right & $\begin{array}{l}\text { This is a copy of an article published in the Thyroid @2011, Mary A nn } \\
\text { Liebert, Inc.; Thy roid is available online at: http://online.liebertpub.com. }\end{array}$ \\
\hline
\end{tabular}




\title{
Risk for Progression to Overt Hypothyroidism in an Elderly Japanese Population with Subclinical Hypothyroidism
}

\author{
Misa Imaizumi, ${ }^{1,2}$ Nobuko Sera, ${ }^{1}$ Ikuko Ueki, ${ }^{2}$ Ichiro Horie, ${ }^{2}$ Takao Ando, ${ }^{2}$ Toshiro Usa, ${ }^{2}$ Shinichiro Ichimaru, ${ }^{1}$ \\ Eiji Nakashima, ${ }^{3}$ Ayumi Hida, ${ }^{1}$ Midori Soda, ${ }^{1}$ Tan Tominaga, ${ }^{4}$ Kiyoto Ashizawa, ${ }^{5}$ Renju Maeda, \\ Shigenobu Nagataki, ${ }^{2}$ and Masazumi Akahoshi ${ }^{1}$
}

Background: Few population-based studies report the changes with time in thyroid function tests in patients with subclinical hypothyroidism. We compared the risk for developing overt hypothyroidism in patients with subclinical hypothyroidism and euthyroid controls from the same population of elderly Japanese. We also sought associations of selected parameters with the development of overt hypothyroidism in the subclinical hypothyroid and euthyroid groups.

Methods: We measured thyrotropin (TSH) and free thyroxine (T4) levels at baseline examinations performed from 2000 to 2003 in the cohort of Japanese atomic-bomb survivors and identified 71 patients with spontaneous subclinical hypothyroidism (normal free T4 and TSH $>4.5 \mathrm{mIU} / \mathrm{L}$ without a history of thyroid treatment, mean age 70 year) and 562 euthyroid controls. We re-examined TSH and free T4 levels an average of 4.2 years later (range, 1.9-6.9).

Results: The risk for progression to overt hypothyroidism was significantly increased in subclinical hypothyroid patients $(7.0 \%)$ compared with control subjects (1.6\%) after adjusting for age and sex (odds ratio, $4.56 ; p=0.009$ ). Higher baseline TSH levels were associated with progression from subclinical to overt hypothyroidism $(p=0.02)$ in the multivariate analysis, including age, sex, antithyroid peroxidase antibody, and ultrasonography (US) findings. The analysis using binary TSH data suggested that a TSH level $>8 \mathrm{mIU} / \mathrm{L}$ was a predictive value for development of overt hypothyroidism $(p=0.005)$. On the other hand, serum TSH levels spontaneously normalized in 38 (53.5\%) of the patients with subclinical hypothyroidism. In the multivariate analysis, normalization of TSH levels was associated with lower baseline TSH levels $(p=0.004)$ and normal and homogenous thyroid US findings $(p=0.04)$. Atomic-bomb radiation dose was not associated with subclinical hypothyroidism or its course.

Conclusions: Subclinical hypothyroidism was four times more likely to be associated with development of overt hypothyroidism than euthyroid controls in the sample population of Japanese elderly. TSH levels in half of the patients normalized spontaneously when assessed after an average follow-up period of 4.2 years. Baseline TSH level and thyroid US findings are potential predictors of future thyroid function in subclinical hypothyroidism.

\section{Introduction}

Subclinical hypothyroidism, as defined by elevated $\checkmark$ thyrotropin (TSH) levels along with normal free thyroxine (FT4) levels, is a common disorder, especially in the elderly. Its prevalence is $4 \%-10 \%$ (1), increasing with age to $20 \%$ (2). Subclinical hypothyroidism is known to be associated with progression of overt hypothyroidism $(3,4)$. However, as far as we know, only one study demonstrated an increased risk for developing overt hypothyroidism in patients with subclinical hypothyroidism compared with euthyroid controls in a population-based study. In the 20-year follow-up of the Whickham cohort in the United Kingdom, elevated serum TSH levels ( $>6 \mathrm{mU} / \mathrm{L}$ ) measured by a first-generation TSH radioimmunoassay at the baseline period between 1972 and 1974 were predictive of progression to overt hypothyroidism

Departments of ${ }^{1}$ Clinical Studies and ${ }^{3}$ Statistics, Radiation Effects Research Foundation, Hiroshima, Japan.

${ }^{2}$ First Department of Internal Medicine, Graduate School of Biomedical Sciences, Nagasaki University, Nagasaki, Japan.

${ }^{4}$ Hakujuji Hospital, Fukuoka, Japan.

${ }^{5}$ Saiseikai Nagasaki Hospital, Nagasaki, Japan. 
(odds ratio versus controls with serum TSH levels $\leq 6 \mathrm{mU} / \mathrm{L}$, 14; 95\% confidence interval, 9-24) (5). Recently, an expert panel defined subclinical hypothyroidism as a serum TSH level > 4.5 IU/L measured by current assays and normal FT4 (3). In 1- to 10-year follow-up hospital-based studies of patients with subclinical hypothyroidism with or without underlying thyroid diseases, $18 \%-33 \%$ of patients developed overt hypothyroidism, whereas TSH levels normalized in $4 \%-$ $37 \%$ of them (6-9). However, it has not been evaluated whether and how much subclinical hypothyroidism, defined by using a current TSH assay, was associated with an increased risk for developing overt hypothyroidism in comparison with euthyroid controls. Further, in the elderly, the hormonal outcome of subclinical hypothyroidism defined as serum TSH levels $>4.5 \mathrm{IU} / \mathrm{L}$ is more uncertain because the upper reference limit of TSH is likely to increase with age (10).

The prevalence of subclinical hypothyroidism in Japan, where iodine intake is sufficient, is $5.8 \%$ in adults (mean age, 51.3 year) (11) and $10.2 \%$ in somewhat older adults (mean age, 58.5 year) (12). Here we investigated a risk for progression to overt hypothyroidism in subclinical hypothyroidism compared with euthyroid controls among the Japanese elderly (mean age, 70 year) and the clinical parameters related to hormonal outcomes.

\section{Materials and Methods}

\section{Participants}

The Adult Health Study (AHS) is a clinical program established in 1958 by the Radiation Effects Research Foundation (RERF), formerly the Atomic Bomb Casualty Commission, comprising Hiroshima and Nagasaki atomic-bomb survivors. The AHS biennial health examinations provide clinical information that is complementary to death and tumor registry data. A detailed description of the project has been published elsewhere $(13,14)$. Monitoring of atomicbomb survivors has provided the opportunity to evaluate thyroid function in a population-based study. Among ambulatory AHS participants, as shown in Figure 1, 763 of the 1623 who had undergone baseline thyroid examinations between 2000 and 2003 also underwent follow-up thyroid examinations between 2004 and 2007 at the Nagasaki RERF Laboratory. The mean follow-up period was 4.2 years (range, 1.9-6.9). In selecting among the 763 for the present study, we excluded 67 people who at baseline had a history of thyroid disease treatment (surgery, radiation, thyroid hormone, or antithyroid medication) and 7 who had later undergone thyroid tumor surgery, leaving 689 subjects. Subclinical hypothyroidism was defined as elevated TSH levels ( $>4.5 \mathrm{mIU}$ / L) based on expert reviews $(3,4)$ and normal FT4 levels (reference range, $0.71-1.52 \mathrm{ng} / \mathrm{dL}$ [9.1-19.6 pmol/L]), and euthyroid control was defined as normal TSH (reference range, $0.45-4.5 \mathrm{IU} / \mathrm{mL}$ ) and FT4 levels. At the baseline examination, $71(10.3 \%)$ had subclinical hypothyroidism-68 (96\%) had serum TSH levels below $10 \mathrm{mIU} / \mathrm{L}$-whereas $562(81.6 \%)$ were euthyroid. At the follow-up examination, we defined patients with overt hypothyroidism as those being treated with thyroid hormone for decreased FT4 or continuous high ( $>10 \mathrm{mIU} / \mathrm{mL}$ ) TSH levels and those with decreased FT4 and elevated TSH levels. We used Dosimetry System 2002 to estimate the thyroid atomic-bomb radiation doses of individual subjects (15). The RERF Human Investigation Committee re-

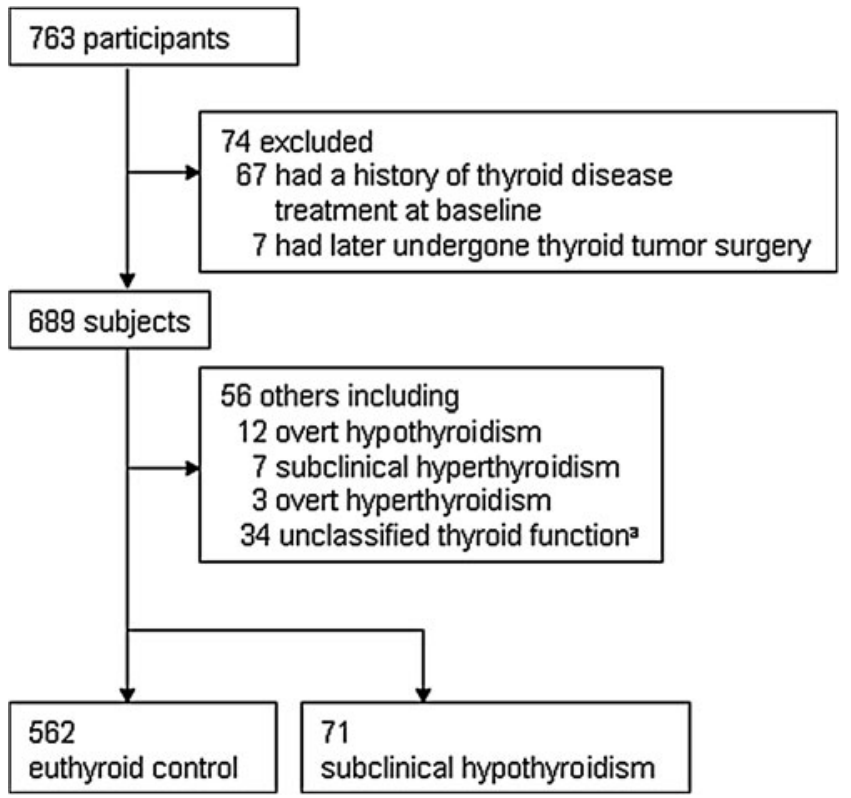

FIG. 1. Breakdown of participants into the study subjects. among 34 subjects of unclassified thyroid function, 1 had increased FT4 level ( $>1.52 \mathrm{ng} / \mathrm{dL})$ and increased TSH level $(>4.5 \mathrm{IU} / \mathrm{L}), 6$ had increased FT4 levels $(>1.52 \mathrm{ng} / \mathrm{dL})$ and normal TSH levels, and 27 had decreased FT4 levels $(<0.71 \mathrm{ng} / \mathrm{dL})$ and normal TSH level. FT4, free thyroxine; $\mathrm{TSH}$, thyrotropin.

viewed and approved this study, and all participants provided written informed consents.

\section{Clinical examination and laboratory methods}

At biennial clinical examinations, a trained nurse recorded information on current and past disease and medications and drew blood samples for the thyroid function and antithyroid peroxidase antibody (TPOAb) tests. We determined serum FT4and TSH levels in a single serum sample with a Lumipulse 1200 analyzer using an immunometric technique based on chemiluminescence (Fujirebio Diagnostics, Inc.). Lyphochek Immunoassay TMJ Control (Bio-Rad Laboratories) was used for quality control at every measurement. We measured TPOAb with an enzyme-linked immunosorbent assay (Medical \& Biological Laboratories Co., Ltd.), and classified subjects as positive when their serum concentrations were $\geq 10 \mathrm{IU} / \mathrm{mL}$. All participants underwent thyroid ultrasonography (US) (Aloka SSD 2000; Aloka Co Ltd) by two certified ultrasonographers. US images were recorded on film for review by two physicians specializing in the thyroid (M.I. and N.S.) without knowledge of clinical or laboratory data, or thyroid atomicbomb radiation dose. Disagreements were resolved by discussion. Decreased or heterogeneous echogenicity was defined as a positive US finding that met the generally accepted standards of diffuse parenchymal hypoechogenicity or a heterogeneous echo pattern of the thyroid gland $(16,17)$.

\section{Statistical analysis}

We used the $\chi^{2}$ test, Fisher exact test, or Wilcoxon rank sum test to compare variations between groups and multivariate logistic regression analysis to evaluate the association 
between the prognosis of subclinical hypothyroidism and clinical factors. We conducted analyses with SAS software running on a UNIX System (SAS/STAT Software, Release 9.0.: SAS Inst. Inc.). All significance tests were two-sided, and $p$-values $<0.05$ were considered significant.

\section{Results}

\section{Baseline clinical characteristics of patients with subclinical hypothyroidism versus control subjects}

Compared with control subjects (Table 1), patients with subclinical hypothyroidism were older $(p=0.03$, Table 1$)$ and did not differ in sex ratio $(p=0.18)$, duration of follow-up $(p=0.22)$, or thyroid atomic-bomb radiation dose $(p=0.36)$. They had significantly higher TSH levels $(p<0.001)$, lower FT4 levels $(p=0.003)$, and higher positive rates for TPOAb $(p<0.001)$. Thyroid atomic-bomb radiation dose was not associated with subclinical hypothyroidism in logistic analysis adjusted for age and $\operatorname{sex}(p=0.62$, data not shown).

\section{Progression from subclinical hypothyroidism to overt hypothyroidism}

A comparison of thyroid function at follow-up between euthyroid controls and patients with subclinical hypothyroidism at baseline is shown in Table 2. The rate of progression to overt hypothyroidism was significantly higher for patients with subclinical hypothyroidism (7.0\%) than for control subjects $(1.6 \%)(p=0.01$, Table 2$)$. In logistic regression analysis adjusted for age and sex, the odds ratio of developing overt hypothyroidism for patients versus controls was 4.56 (95\% confident interval, 1.46, 14.25) ( $p=0.009)$. Baseline TSH levels in patients who progressed to overt hypothyroidism

Table 1. Baseline Characteristics and Thyroid StATUS OF PARTICIPANTS

\begin{tabular}{|c|c|c|c|}
\hline & $\begin{array}{l}\text { Euthyroid } \\
\text { controls }\end{array}$ & $\begin{array}{l}\text { Patients with } \\
\text { subclinical } \\
\text { hypothyroidism }\end{array}$ & $\mathrm{p}$ \\
\hline Number & 562 & 71 & \\
\hline $\begin{array}{l}\text { Age [mean } \pm \text { SD } \\
\text { (range), years] }\end{array}$ & $8 \pm 7(54-87)$ & $70 \pm 6(55-86)$ & 0.03 \\
\hline Sex (M:F) & $200: 362$ & $31: 40$ & 0.18 \\
\hline $\begin{array}{l}\text { TSH (mean } \pm \text { SD, } \\
\text { mIU /L) }\end{array}$ & $2.11 \pm 0.93$ & $6.10 \pm 1.71$ & $<0.0$ \\
\hline $\begin{array}{l}\text { FT4 }(\text { mean } \pm S D, \\
\text { ng/dL) }\end{array}$ & $1.01 \pm 0.16$ & $0.95 \pm 0.15$ & 0.0 \\
\hline $\begin{array}{l}\text { Positive for TPOAb } \\
{[n(\%)]}\end{array}$ & $63(11.2)$ & $18(25.4)$ & $<0.0$ \\
\hline $\begin{array}{l}\text { Follow-up duration } \\
\quad(\text { mean } \pm S D, \text { years })\end{array}$ & $4.3 \pm 0.7$ & $4.2 \pm 0.6$ & 0.22 \\
\hline $\begin{array}{l}\text { Thyroid atomic-bomb } \\
\text { radiation dose } \\
\text { (mean } \pm S D, m G y)\end{array}$ & $446 \pm 618$ & $406 \pm 703$ & 0.36 \\
\hline$<5 \mathrm{mGy}[n(\%)]$ & $190(48.6)$ & $31(63.3 \%)$ & \\
\hline 5-1000 mGy [n (\%)] & $138(35.3)$ & $10(20.4 \%)$ & \\
\hline$>1000$ mGy $[n(\%)]$ & $63(16.1)$ & $8(16.3 \%)$ & 0.09 \\
\hline
\end{tabular}

${ }^{\mathrm{a}}$ To convert values to picomoles per liter, multiply by 12.87 .

${ }^{\mathrm{b}}$ Estimated thyroid atomic-bomb radiation dose was available for 391 euthyroid controls and 49 patients with subclinical hypothyroidism.

M, male; F, female; FT4, free thyroxine; TSH, thyrotropin; TPOAb, antithyroid peroxidase antibody.
Table 2. Outcomes of Thyroid Function at Follow-Up

\begin{tabular}{lccc}
\hline & \multicolumn{1}{c}{ At basal examination, $\mathrm{n} \mathrm{( \% )}$} & \\
\cline { 2 - 3 } & $\begin{array}{c}\text { Euthyroid } \\
\text { controls } \\
(\mathrm{n}=562)\end{array}$ & $\begin{array}{c}\text { Patients with } \\
\text { subclinical } \\
\text { hypothyroidism } \\
(\mathrm{n}=71)\end{array}$ & $\mathrm{p}$ \\
\hline Outcome at follow-up & $511(90.9)$ & $38(53.5)$ & $<0.001$ \\
$\begin{array}{l}\text { Normal thyroid function } \\
\begin{array}{l}\text { Subclinical } \\
\text { hypothyroidism }\end{array}\end{array}$ & $22(3.9)$ & $27(38.0)$ & $<0.001$ \\
$\begin{array}{l}\text { Overt hypothyroidism } \\
\text { Other }\end{array}$ & $9(1.6)$ & $5(7.0)$ & 0.01 \\
\hline
\end{tabular}

${ }^{a}$ Among 20 subjects, 3 had overt hyperthyroidism (TSH $<0.45 \mathrm{IU} /$ $\mathrm{L}$ and FT4 $>1.52 \mathrm{ng} / \mathrm{dL}$ ), 4 had subclinical hyperthyroidism (TSH $<0.45 \mathrm{IU} / \mathrm{L}$ and normal FT4), 9 had decreased FT4 levels $(<0.71 \mathrm{ng} /$ $\mathrm{dL}$ ) and normal TSH levels, and 4 had increased FT4 levels $(>1.52 \mathrm{ng} / \mathrm{dL})$ and normal TSH levels.

${ }^{\mathrm{b}}$ One patient had subclinical hyperthyroidism.

ranged from 5.18 to 11.15 . Table 3 shows the number of patients in three groups at follow-up: normal TSH, subclinical hypothyroidism, and overt hypothyroidism classified according to the basal clinical parameters. The $p$-value of each parameter is for heterogeneity of distribution of patients into three groups at follow-up. In this analysis, TSH level at baseline was associated with thyroid function at follow-up. In multivariate analysis adjusted for age, sex, TPOAb, and US findings, higher serum TSH levels were significantly associated with development of overt hypothyroidism $(p=0.02$, Table 4$)$. In the analysis using binary TSH data (TSH level $>6,7,8$, and 9 compared with TSH level $\leq 6,7,8$, and 9, respectively), TSH levels $>8$ and $9 \mathrm{mIU} / \mathrm{L}$ were associated with the development of overt hypothyroidism ( $p=0.005$ and 0.004 , respectively), whereas TSH level $>6$ and $7 \mathrm{mIU} / \mathrm{L}$ were not (both $p=0.06$ ) adjusting for age, sex, TPOAb, and US findings, suggesting that a TSH level more than around $8 \mathrm{mIU} / \mathrm{L}$ was a predictive value for development of overt hypothyroidism. Thyroid atomicbomb radiation dose was not associated with progression to overt hypothyroidism ( $p=0.83$, data not shown).

\section{Spontaneous normalization of TSH}

At the follow-up examination, 38 (53.5\%) of the patients with subclinical hypothyroidism spontaneously regained normal TSH levels (Table 2) and TSH levels of all the patients except 3 decreased $>1.0 \mathrm{mIU} / \mathrm{L}$. Normalization was not observed in patients whose baseline serum TSH level was $>8 \mathrm{mIU} / \mathrm{L}$ and it was observed in $67.6 \%$ of patients with negative US findings and $39.4 \%$ with positive US findings (Table 3). In multivariate analysis, TSH normalization was negatively associated with serum TSH level $(p=0.004)$ and with positive US findings $(p=0.04)$ and was not significantly associated with age, sex, or TPOAb positivity (Table 4). Thyroid atomic-bomb radiation dose was not associated with TSH normalization ( $p=0.89$, data not shown).

\section{Discussion}

In this 4.2-year (range, 1.9-6.9) follow-up study of the Japanese elderly (mean age, 70 year), we first demonstrated that subclinical hypothyroidism, defined as TSH levels $>4.5 \mathrm{IU} / \mathrm{L}$, 
Table 3. Baseline Clinical Parameters in Patients with Subclinical Hypothyroidism by Thyroid Function at Follow-Up

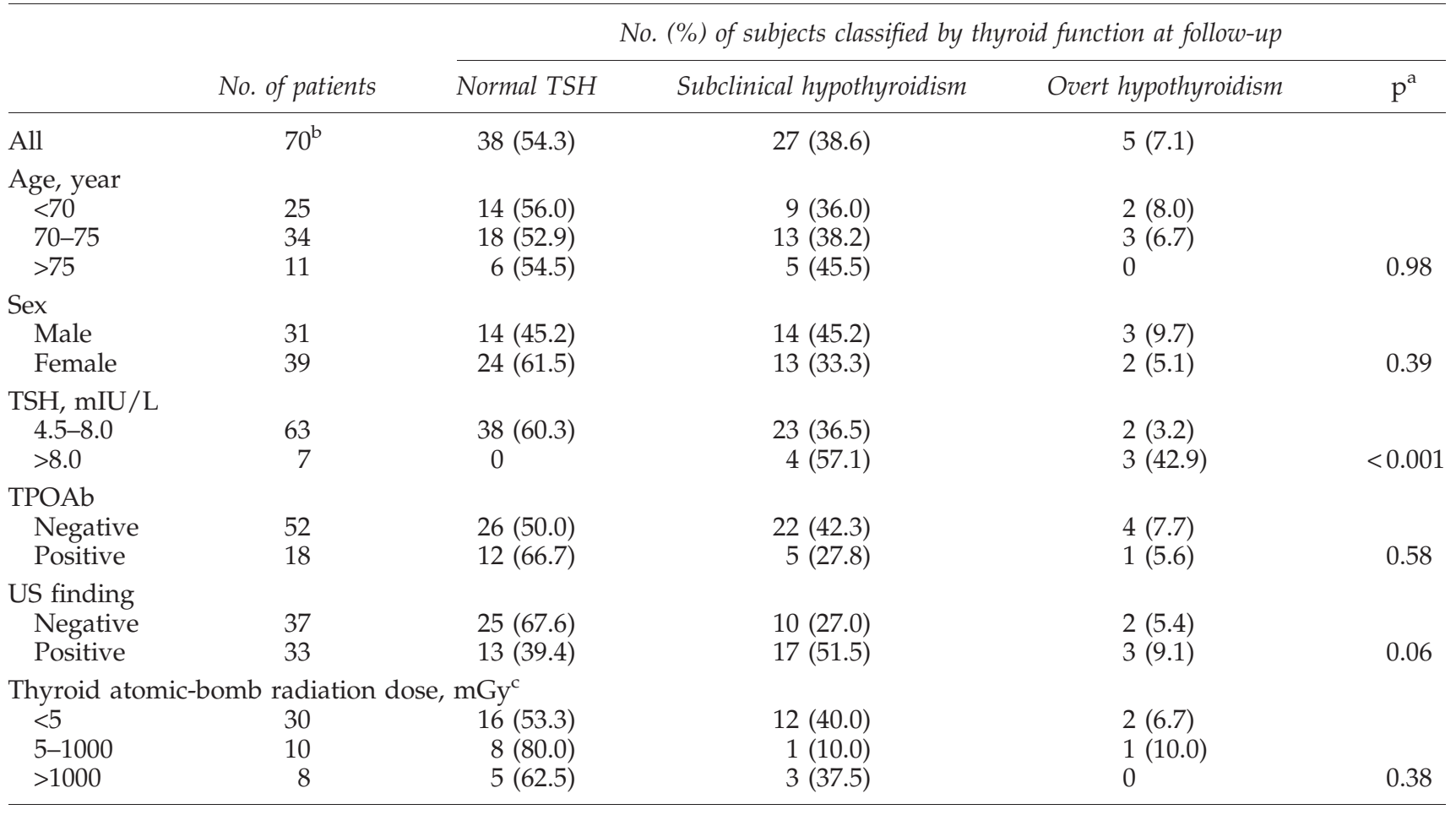

${ }^{a}$ Fisher exact test for the distribution of patients into three groups at follow-up: normal TSH, subclinical hypothyroidism, and overt hypothyroidism

bTotal is 70, not 71, because one patient had subclinical hyperthyroidism at follow-up.

${ }^{c}$ Estimated thyroid atomic-bomb radiation dose was available in 48 patients among 70 patients with subclinical hypothyroidism.

US, ultrasonography.

was significantly associated with progression to overt hypothyroidism compared with euthyroid controls. The odds ratio of developing overt hypothyroidism for subclinical hypothyroidism versus euthyroid control was 4.56 , which was lower than that in the Whickham study (odds ratio, 14) (5). The lower odds ratio may be related to the fact that our study included more patients with mild subclinical hypothyroidism because we used a current TSH assay and a lower TSH cut-off point. Further, older study subjects and shorter observation periods in this study could also be related to the decreased odds ratio. Although the present results were obtained in atomic-bomb survivors, the result can be generalized to the Japanese population because the atomic-bomb radiation dose was not associated with subclinical hypothyroidism or its natural course in this study and no influence on prevalence of thyroid dysfunction and positivity of thyroid autoantibody was observed in atomic-bomb survivors in the previous study (18). Recent reports recommend using an age-, gender-, and ethnicity-specific TSH reference range $(10,19)$, but a Japanese age-specific TSH reference range is not available. We were also concerned that it has not been evaluated whether agespecific reference range influences risks for various endpoints, including development of overt hypothyroidism. Therefore, we used a common definition of subclinical hypothyroidism as a serum TSH level of $4.5 \mathrm{mIU} / \mathrm{L}$ or greater based on expert reviews $(3,4)$. Using an age-specific TSH cut-off point may

Table 4. Multivariate Analysis of Basal Clinical Parameters Related to Thyroid Function at Follow-Up

\begin{tabular}{|c|c|c|c|c|}
\hline \multirow[b]{3}{*}{ Basal parameter } & \multicolumn{4}{|c|}{ Thyroid function at follow-up } \\
\hline & \multicolumn{2}{|c|}{ Normal TSH ${ }^{\mathrm{a}}$} & \multicolumn{2}{|c|}{ Overt hypothyroidism ${ }^{\mathrm{b}}$} \\
\hline & OR $(95 \% C I)$ & $p$ & OR $(95 \% C I)$ & $p$ \\
\hline Age, per 10 years & $0.66(0.25,1.75)$ & 0.40 & $0.88(0.16,4.72)$ & 0.88 \\
\hline Women & $1.05(0.32,3.51)$ & 0.93 & $0.32(0.03,3.13)$ & 0.33 \\
\hline $\mathrm{TSH}$, per $1 \mathrm{mU} / \mathrm{L}$ & $0.41(0.22,0.76)$ & 0.004 & $1.74(1.09,2.79)$ & 0.02 \\
\hline Positive for TPOAb & $2.16(0.53,8.90)$ & 0.29 & $1.04(0.08,14.02)$ & 0.98 \\
\hline Positive US finding ${ }^{c}$ & $0.28(0.08,0.96)$ & 0.04 & $1.27(0.21,7.75)$ & 0.67 \\
\hline
\end{tabular}

"The reference group for "Normal TSH" had TSH levels $>4.5 \mathrm{mU} / \mathrm{L}$ or thyroid hormone therapy at follow-up.

bThe reference group for "Overt hypothyroidism" had normal FT4 levels and no thyroid hormone therapy at follow-up.

'Indicates presence of diffuse hypoechogenicity or heterogeneous echo pattern of the thyroid in US examination. 
increase the odds ratio of developing overt hypothyroidism in subclinical hypothyroidism.

Our study showed that baseline serum TSH level, but not positivity of TPOAb, was prognostic in a multivariate analysis, which is consistent with a prospective Spanish study (9). We also clearly demonstrated that a TSH level $>8 \mathrm{mIU} / \mathrm{L}$ was predictive for development of overt hypothyroidism. Further, since the baseline TSH level of all patients in our study whose condition spontaneously normalized was $<8 \mathrm{mIU} / \mathrm{L}$, care should be exercised when initiating treatment for such elderly patients. Our sample population was small, however, and from an iodine-sufficient country, so an appropriately powered prospective study is needed to examine the TSH threshold for predicting hormonal prognosis of subclinical hypothyroidism in other countries.

On the other hand, about half of the patients spontaneously regained normal TSH levels. The rate of TSH normalization from spontaneous subclinical hypothyroidism in this study population (53.5\% over 4.2 years, mean age, 70 year) was higher than that reported in the United Kingdom (5.5\% over 1 year, age, 60 and over) (6) and Spain (37.4\% over 2.6 year, mean age, 62 year) (9) although the results could be less comparable because of different observation periods. Our finding of mild subclinical hypothyroidism (TSH $<10 \mathrm{mIU} /$ L) in $96 \%$ of our patients contrasts with the $74 \%$ of patients in the United States population-based study (mean age, 56 year) (2). Since lower serum TSH levels were significantly associated with TSH normalization in our multivariate analysis, the high frequency of mild subclinical hypothyroidism in our population is probably one of the reasons that TSH level spontaneously normalized in a large number of patients. Indeed, all patients showing spontaneous normalization of TSH levels had serum levels $<8 \mathrm{mIU} / \mathrm{L}$ at baseline.

Autoimmune thyroiditis is the major cause of subclinical hypothyroidism (1). In surveys in Europe, $40 \%-67 \%$ of patients who had high serum TSH concentrations also had high serum antibody values $(6,20)$. Further, thyroid autoantibody was found to have possible prognostic relevance in subclinical hypothyroidism $(5,7,8)$. However, multivariate analysis adjusted by age, sex, TSH levels, and other clinical parameters did not confirm the association between TPOAb and progression to overt hypothyroidism, and only TSH level was significant in a Spanish study (9), which is consistent with our multivariate analysis. It has been suggested that US thyroid findings (decreased and heterogenous echogenicity) are associated with autoiummune thyroid disease and thyroid dysfunction $(16,17,21)$ and that US is a useful tool for the diagnosis of antibody-negative autoimmune thyroiditis (22). Rosário and colleagues recently reported the possibility that US findings are useful in determining the prognosis of TPOAb-negative mild subclinical hypothyroidism (23). Our study clearly demonstrated that a negative US finding, rather than negative TPOAb, was associated with TSH normalization of subclinical hypothyroidism in a multivariate analysis. Taken together, histological change of the thyroid detected by US may be more relevant to the prognosis of subclinical hypothyroidism in patients with autoimmune thyroiditis. Our positive US finding, however, was not significantly associated with progression to overt hypothyroidism, probably because of the small case number.

In the present study, the positive rate for TPOAb was only $25.4 \%$ in patients with subclinical hypothyroidism, which was much lower than that in the Spanish hospital-based study $(76 \%)(9)$. A similar low positive rate for TPOAb $(20.5 \%)$ was reported in patients with subclinical hypothyroidism in another Japanese population study (11), suggesting that a nonautoimmune etiology might be also responsible for the mild subclinical hypothyroidism found in Japan. One possible etiology is iodine diet. The Japanese consume excessive iodine (24). Excess iodine intake can induce overt and subclinical hypothyroidism in autoantibody-negative people $(25,26)$, and in a Japanese population-based study, overt and subclinical hypothyroidism (TSH $>5.0 \mathrm{mIU} / \mathrm{L}$ ) was more prevalent in individuals with high urinary iodine concentration than in those with normal urinary iodine concentration among thyroid autoantibody-negative patients (27). When iodine intake was restricted, the serum TSH concentrations returned to normal in autoantibody-negative patients, but not in autoantibody-positive patients (28). Urinary iodine excretion in the Japanese, however, fluctuates from 0.1 to $30 \mathrm{mg} /$ day, depending on seaweed intake (29). That might, at least in part, be related to the high rate of TSH normalization. We could not confirm the association of iodine diet with TSH level in our study population, however, because we did not have iodine consumption data.

A limitation of our study was that thyroid status was based on a single blood test whose reproducibility was not assessed. It is possible that some participants with TSH levels around the cutoff point $(4.5 \mathrm{mIU} / \mathrm{L})$ might have been misclassified. Further, TSH levels of patients with subclinical hypothyroidism might have fluctuated for a number of reasons during the study period and rates of TSH normalization and progression to overt hypothyroidism would be affected by duration of the observation period. However, one of the strengths of this study is that we could evaluate the prognosis of subclinical hypothyroidism, although based on single TSH determinations, in comparison with euthyroid controls in a population-based study. A further study conducting measurements of thyroid function at regular intervals is necessary for better understanding of the natural course of thyroid function in patients with subclinical hypothyroidism.

In the present study of the Japanese elderly, the risk for progression to overt hypothyroidism was significantly increased in patients with subclinical hypothyroidism, whereas about half of the patients spontaneously regained normal TSH levels. Lower TSH levels and negative US findings were associated with TSH normalization.

\section{Acknowledgments}

The RERF, Hiroshima and Nagasaki, Japan, is a private, nonprofit foundation funded by the Japanese Ministry of Health, Labour and Welfare (MHLW) and the U.S. Department of Energy (DOE), with the latter provided in part through the U.S. National Academy of Sciences (NAS). This publication was supported by RERF Research Protocol \# 2-99 and B41-05. We thank Mr. Isao Sakamoto and Mr. Katsuhisa Yamasaki for technical assistance, Mr. Tomohiro Ikeda for general assistance, and Dr. Miriam Bloom (SciWrite Biomedical Writing \& Editing Services) for professional editing.

\section{Disclosure Statement}

The authors declare that no competing financial interests exist. 


\section{References}

1. Biondi B, Cooper DS 2008 The clinical significance of subclinical thyroid dysfunction. Endocr Rev 29:76-131.

2. Canaris GJ, Manowitz NR, Mayor G, Ridgway EC 2000 The Colorado thyroid disease prevalence study. Arch Intern Med 160:526-534.

3. Surks MI, Ortiz E, Daniels GH, Sawin CT, Col NF, Cobin RH, Franklyn JA, Hershman JM, Burman KD, Denke MA, Gorman C, Cooper RS, Weissman NJ 2004 Subclinical thyroid disease: scientific review and guidelines for diagnosis and management. JAMA 291:228-238.

4. Helfand M 2004 Screening for subclinical thyroid dysfunction in nonpregnant adults: a summary of the evidence for the U.S. Preventive Services Task Force. Ann Intern Med 140:128-141.

5. Vanderpump MP, Tunbridge WM, French JM, Appleton D, Bates D, Clark F, Grimley Evans J, Hasan DM, Rodgers H, Tunbridge F, Young E 1995 The incidence of thyroid disorders in the community: a twenty-year follow-up of the Whickham Survey. Clin Endocrinol (Oxf) 43:55-68.

6. Parle JV, Franklyn JA, Cross KW, Jones SC, Sheppard MC 1991 Prevalence and follow-up of abnormal thyrotrophin (TSH) concentrations in the elderly in the United Kingdom. Clin Endocrinol (Oxf) 34:77-83.

7. Rosenthal MJ, Hunt WC, Garry PJ, Goodwin JS 1987 Thyroid failure in the elderly. Microsomal antibodies as discriminant for therapy. JAMA 258:209-213.

8. Huber G, Staub JJ, Meier C, Mitrache C, Guglielmetti M, Huber P, Braverman LE 2002 Prospective study of the spontaneous course of subclinical hypothyroidism: prognostic value of thyrotropin, thyroid reserve, and thyroid antibodies. J Clin Endocrinol Metab 87:3221-3226.

9. Diez JJ, Iglesias P 2004 Spontaneous subclinical hypothyroidism in patients older than 55 years: an analysis of natural course and risk factors for the development of overt thyroid failure. J Clin Endocrinol Metab 89:4890-4897.

10. Surks MI, Hollowell JG 2007 Age-specific distribution of serum thyrotropin and antithyroid antibodies in the US population: implications for the prevalence of subclinical hypothyroidism. J Clin Endocrinol Metab 92:4575-4582.

11. Kasagi $K$, Takahashi $N$, Inoue G, Honda T, Kawachi $Y$, Izumi Y 2009 Thyroid function in Japanese adults as assessed by a general health checkup system in relation with thyroid-related antibodies and other clinical parameters. Thyroid 19:937-944.

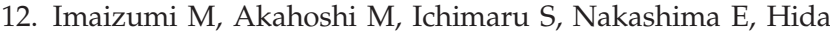
A, Soda M, Usa T, Ashizawa K, Yokoyama N, Maeda R, Nagataki S, Eguchi K 2004 Risk for ischemic heart disease and all-cause mortality in subclinical hypothyroidism. J Clin Endocrinol Metab 89:3365-3370.

13. Atomic Bomb Casualty Commission 1962 Research Plan for Joint ABCC-NIH Adult Health Study in Hiroshima and Nagasaki, ABCC Technical Report 11-62, Hiroshima and Nagasaki, Japan.

14. Yamada M, Wong FL, Fujiwara S, Akahoshi M, Suzuki G 2004 Noncancer disease incidence in atomic bomb survivors, 1958-1998. Radiat Res 161:622-632.

15. Young R, Kerr G (eds) (2005) Reassessment of the Atomic Bomb Radiation Dosimetry for Hiroshima and Nagasaki, Dosimetry System 2002, Report of the Joint US-Japan Working Group. Radiation Effects Research Foundation, Hiroshima.

16. Vejbjerg P, Knudsen N, Perrild H, Laurberg P, Pedersen IB, Rasmussen LB, Ovesen L, Jorgensen T 2006 The association between hypoechogenicity or irregular echo pattern at thyroid ultrasonography and thyroid function in the general population. Eur J Endocrinol 155:547-552.

17. Pedersen OM, Aardal NP, Larssen TB, Varhaug JE, Myking O, Vik-Mo H 2000 The value of ultrasonography in predicting autoimmune thyroid disease. Thyroid 10:251-259.

18. Imaizumi M, Usa T, Tominaga T, Neriishi K, Akahoshi M, Nakashima E, Ashizawa K, Hida A, Soda M, Fujiwara S, Yamada M, Ejima E, Yokoyama N, Okubo M, Sugino K, Suzuki G, Maeda R, Nagataki S, Eguchi K 2006 Radiation dose-response relationships for thyroid nodules and autoimmune thyroid diseases in Hiroshima and Nagasaki atomic bomb survivors 55-58 years after radiation exposure. JAMA 295:1011-1022.

19. Boucai L, Hollowell JG, Surks MI 2011 An approach for development of age-, gender-, and ethnicity-specific thyrotropin reference limits. Thyroid 21:5-11.

20. Tunbridge WM, Evered DC, Hall R, Appleton D, Brewis M, Clark F, Evans JG, Young E, Bird T, Smith PA 1977 The spectrum of thyroid disease in a community: the Whickham survey. Clin Endocrinol (Oxf) 7:481-493.

21. Raber W, Gessl A, Nowotny P, Vierhapper H 2002 Thyroid ultrasound versus antithyroid peroxidase antibody determination: a cohort study of four hundred fifty-one subjects. Thyroid 12:725-731.

22. Nys P, Cordray JP, Merceron RE 2009 Etiologic discussion and clinical relevance of thyroid ultrasonography in subclinical hypothyroidism. A retrospective study in 1845 patients. Ann Endocrinol (Paris) 70:59-63.

23. Rosario PW, Bessa B, Valadao MM, Purisch S 2009 Natural history of mild subclinical hypothyroidism: prognostic value of ultrasound. Thyroid 19:9-12.

24. Nagataki S 2008 The average of dietary iodine intake due to the ingestion of seaweeds is $1.2 \mathrm{mg} /$ day in Japan. Thyroid 18:667-668.

25. Yokoyama N, Nagataki S 2002 Disorders of iodine excess. In: Wass J, Shalet S (eds) Oxford Textbook of Endocrinology and Diabetes. Oxford University Press Inc., New York, pp 380-392.

26. Roti E, Vagenakis AG 2005 Effect of excess iodine: clinical aspects. In: Braverman LE, Utiger RD (eds) Werner \& Ingbar's The Thyroid: A Fundamental and Clinical Text, 9th edition. Lippincott Williams \& Wilkins, Philadelphia, pp 288-305.

27. Konno N, Makita H, Yuri K, Iizuka N, Kawasaki K 1994 Association between dietary iodine intake and prevalence of subclinical hypothyroidism in the coastal regions of Japan. J Clin Endocrinol Metab 78:393-397.

28. Konno N, Yuri K, Taguchi H, Miura K, Taguchi S, Hagiwara K, Murakami S 1993 Screening for thyroid diseases in an iodine sufficient area with sensitive thyrotrophin assays, and serum thyroid autoantibody and urinary iodide determinations. Clin Endocrinol (Oxf) 38:273-281.

29. Nagataki S, Shizume K, Nakao K 1967 Thyroid function in chronic excess iodide ingestion: comparison of thyroidal absolute iodine uptake and degradation of thyroxine in euthyroid Japanese subjects. J Clin Endocrinol Metab 27:638-647.

Address correspondence to: Misa Imaizumi, M.D., Ph.D.

Department of Clinical Studies Radiation Effects Research Foundation 1-8-6 Nakagawa Nagasaki 850-0013 Japan

E-mail: misaima@rerf.or.jp 